PUSTABIBLIA: Journal of Library and Information Science

ISSN 2549-3493 (Print); ISSN 2549-3868 (Online)

DOI: http://dx.doi.org/10.18326/pustabiblia.v4i2.265-282

SK Dirjen Risbang-Kemristekdikti No 23/E/KPT/2019 (Peringkat 4 SINTA)

\title{
Pelayanan Koleksi Surat Kabar Prakemerdekaan di Perpustakaan Nasional Republik Indonesia
}

\author{
Frial Ramadhan Supratman \\ Perpustakaan Nasional Republik Indonesia \\ Email: frialramadhan1@gmail.com \\ Diajukan: 14-06-2020; Direview: 09-07-2020; Diterima: 28-07-2020; \\ Direvisi: 18-07-2020
}

\begin{abstract}
National Library has important role in every countries. One of important role of National Library in several countries are protecting and preserving rare collection produced in the countries. National Library of Indonesia preserves several rare collections, like newspapers, rare books, magazines, photographs and manuscripts. Rare newspaper is one of rare collection of the National Library which has important aspect. Researcher and visitor often benefit rare newwspaper collection as information sources. Pre-independence newspaper always becomes reference source for researcher from many countries. This article aims to analyze of rare newspaper collection in the National Library. This research method is using quantitative method. This research also uses direct observation approach. In direct observation, author checks directly filed condition to find data and information regarding this research. The result of this research is that the demand of reading pre-independence newspaper is little if it is compared with post-independence newspaper. Most of pre-independence newspaper has been broken, but almost 50\% of the newspaper has been converted to microfilm format. Librarian plays important role in preserving and serving pre-independence newspaper. If the demanded pre-independence newspaper is in broken condition and unreadable, librarian should advice user to access microfilm-formated newspaper in Audio Visual Service in National Library of Indonesia.
\end{abstract}

Keywords: Newspaper; Pre-Independence' Collection; National Library of Indonesia 


\begin{abstract}
Abstrak
Perpustakaan nasional memiliki peran yang penting dalam setiap negara. Salah satu peran perpustakaan nasional di berbagai negara adalah menjaga dan melestarikan koleksi langka yang pernah diproduksi di negara tersebut. Perpustakaan Nasional Republik Indonesia menyimpan berbagai macam koleksi langka, seperti surat kabar, buku, majalah, foto, peta hingga naskah. Surat kabar langka termasuk salah satu koleksi Perpustakaan Nasional yang sangat penting. Para peneliti dan pengunjung sering memanfaatkan surat kabar langka sebagai sumber informasi. Surat kabar langka prakemerdekaan seringkali menjadi sumber rujukan para peneliti dari berbagai negara. Makalah ini bertujuan untuk melakukan analisis terhadap koleksi surat kabar prakemerdekaan di Perpustakaan Nasional. Metode penelitian ini adalah dengan menggunakan metode kuantitatif. Penelitian ini menggunakan pendekatan observasi langsung. Dalam observasi langsung, penulis melakukan pemeriksaan langsung terhadap kondisi di lapangan untuk menemukan data dan informasi terkait penelitian. Hasil dari penelitian ini adalah bahwa permintaan untuk membaca surat kabar prakemerdekaan sangat kecil jika dibandingkan dengan surat kabar pasca kemerdekaan. Sebagian besar surat kabar prakemerdekaan sudah dalam keadaan rusak, namun hampir 50\% surat kabar tersebut sudah dialihmediakan dalam bentuk mikrofilm. Pustakawan berperan penting dalam menjaga dan melayani surat kabar prakemerdekaan. Jika surat kabar prakemerdekaan yang diminta sudah rusak dan tidak dapat dibaca, maka pustakawan akan mengarahkan pemustaka untuk mengakses surat kabar yang berbentuk mikrofilm di Layanan Audio Visual, Perpustakaan Nasional Republik Indonesia.
\end{abstract}

Kata kunci: $\quad$ Surat Kabar; Prakemerdekaan; Koleksi; Perpustakaan Nasional Republik Indonesia; Mikrofilm

\title{
1. PENDAHULUAN
}

Perpustakaan merupakan institusi atau tempat masyarakat mencari informasi dan pengetahuan. Informasi dan pengetahuan tersebut tersimpan dalam koleksi perpustakaan berupa buku, majalah, surat kabar, mikrofilm, peta, foto dan lain-lain. Perpustakaan yang menjadi pusat pelestarian khazanah bangsa disebut dengan perpustakaan nasional. Setiap negara memiliki perpustakaan nasional yang berlokasi di ibu kota. Perpustakaan Nasional Republik Indonesia terletak di Jakarta dan sudah berdiri sejak 1988. 
Perpustakaan Nasional RI menyimpan berbagai macam koleksi nasional, baik itu berupa buku, majalah, surat kabar dan lain-lain.

Surat kabar merupakan salah satu koleksi Perpustakaan Nasional RI yang paling berharga. Koleksi ini menyimpan berbagai macam informasi dari mulai peristiwa politik, perubahan sosial, sistem ekonomi, kegiatan kebudayaan hingga pertahanan dan keamanan. Surat kabar sudah ada di Indonesia sejak abad ke-17 berkat adanya mesin cetak yang dibawa oleh Perusahaan Hindia Belanda Timur (Vereeniging Oost Indische Compagnie) (Adam, 2003). Pada awalnya surat kabar digunakan untuk kepentingan pemerintahan, agama dan bisnis. Surat kabar ketika itu digunakan untuk memasang iklan barang dagang agar diketahui oleh para pembeli. Pada akhir abad ke-19 dan awal abad ke-20, banyak surat kabar berbahasa Melayu yang dicetak di Indonesia sehingga perkembangan surat kabar pada masa tersebut memberikan peran yang penting bagi perkembangan literasi dan sejarah bahasa Indonesia.

Para peneliti baik dari Indonesia maupun luar negeri banyak yang mencari informasi melalui surat kabar untuk kebutuhan penelitian. Perpustakaan Nasional RI merupakan institusi yang memiliki surat kabar paling lengkap di Indonesia. Salah satu surat kabar tertua yang dimiliki oleh Perpustakaan Nasional RI adalah Bataviaasch Koloniale Courant (Supratman, 2020). Selain itu terdapat banyak surat kabar berbahasa Belanda dan Melayu-Indonesia yang terbit sejak abad ke-19 hingga masa kontemporer. Namun tidak semua surat kabar dapat dilayankan kepada para pengunjung karena kondisi fisik dari setiap surat kabar berbeda-beda. Hal ini menjadi permasalahan yang penting dalam pelayanan pengunjung di Layanan Surat Kabar Langka. Banyak para peneliti yang ingin membaca surat kabar langka, namun tidak semua surat kabar dapat diberikan kepada pengunjung karena kondisinya sudah rusak. Hal itu juga disebabkan oleh fungsi Perpustakaan Nasional sebagai penjaga kelestarian khazanah bangsa sehingga para pustakawan di sana harus menjaga dan merawat koleksi-koleksi perpustakaan agar tetap lestari dan dimanfaatkan dengan baik. 
Makalah ini bertujuan untuk memberikan gambaran mengenai pelayanan surat kabar langka. Penulis mencoba untuk mendata surat kabar zaman prakemerdekaan untuk mendapatkan gambaran yang jelas mengenai pelayanan surat kabar langka di Perpustakaan Nasional RI. Dalam penelitian ini, terdapat pertanyaan penelitian yang harus dijawab oleh penulis. Pertanyaan penelitian tersebut diantaranya, seberapa besar minat pemustaka atau pengunjung untuk membaca surat kabar prakemerdekaan?; bagaimana kondisi surat kabar prakemerdekaan?; bagaimana pustakawan melakukan pelayanan terhadap pemustaka yang meminta koleksi surat kabar prakemerdekaan?

Dalam penelitian ini penulis lebih fokus pada satu kelompok layanan, yaitu Layanan Surat Kabar Langka. Banyak pengunjung yang datang ke Layanan Surat Kabar Langka untuk membaca berbagai macam koleksi surat kabar. Penelitian ini dilakukan dari Januari hingga Juni 2020 di Layanan Surat Kabar Langka, Perpustakaan Nasional RI yang terletak di Jalan Salemba Raya No.28 A, Senen, Jakarta Pusat, DKI Jakarta.

\section{TINJAUAN PUSTAKA}

Banyak penelitian yang telah membahas mengenai pelayanan perpustakaan, baik itu perpustakan umum, perpustakaan khusus, perpustakaan nasional, hingga perpustakaan sekolah dan perguruan tinggi. Beberapa penelitian sebelumnya menguraikan berbagai macam permasalahan dalam pelayanan perpustakaan, seperti adanya vandalisme, kepuasan pemustaka, dan temu kembali informasi. Setiap kajian tersebut tentu saja memiliki manfaat dan fungsinya sendiri. Kajian yang dilakukan oleh Muhammad, Komariah dan Kurniasih (2019) menunjukan bagaimana para pustakawan memahami perilaku vandalisme yang dilakukan oleh para pengunjung yang berlatar belakang mahasiswa. Berdasarkan kajian tersebut, para penulis menemukan bahwa perpustakaan kampus pun tidak dapat menghindari adanya perilaku vandalisme, baik berupa pengeratan dan pembetotan halaman, perobekan halaman, pengguntingan gambar pada koleksi, pelipatan halaman, pemanfaatan kartu anggota perpustakaan 
orang lain untuk meminjam buku, pengembalian buku yang terlambat dan lain-lain. Untuk itu vandalisme merupakan salah satu masalah yang terjadi di dalam pelayanan perpustakaan. Kemudian terdapat kajian yang dilakukan oleh Hanany dan Sudirman (2019) mengenai kepuasan pemustaka atau pengunjung di Perpustakaan UIN Sunan Gunung Djati Bandung dan pengaruh word of mouth pemustaka. Penelitan ini menunjukan bahwa kepuasan pemustaka merupakan bagian dari indikator sistem pelayanan di dalam suatu perpustakaan. Selain itu terdapat penelitian yang dilakukan oleh Usman dan Narani (2020) mengenai pengelolaan Perpustakaan Madrasah. Dalam penelitian ini terlihat bahwa perpustakaan harus memiliki rencana strategis yang jelas dan terukur. Untuk itu pelayanan yang dilakukan oleh perpustakaan pun menjadi lebih baik. Kemudian terdapat penelitian yang ditulis oleh Oktaviani, Saifudin dan Puspita (2019) mengenai peningkatan kualitas layanan di perpustakaan. Penelitian ini berkesimpulan bahwa keandalan, daya tanggap, jaminan, empati, dan bukti fisik berpengaruh positif terhadap kepuasan pemustaka atau pengunjung.

Selain karya-karya mengenai pelayanan perpustakaan, terdapat juga beberapa karya yang membahas mengenai koleksi. Supratman(2020) membahas mengenai bagaimana fungsi koleksi surat kabar dalam penelitian sejarah global. Penelitian ini menunjukan fungsi surat kabar sebagai data penelitian sejarah. Munisah (2020) melakukan penelitian mengenai kegiatan evaluasi pada koleksi di perpustakaan dalam tinjauan teori dari Evans dan Futas. Evaluasi terhadap koleksi sangatlah penting untuk dilakukan karena dengan adanya evaluasi maka pustakawan akan dapat mengetahui dan mengukur kebutuhan dan kelayakan dari suatu koleksi. Dengan demikian penelitian ini mencoba untuk memberikan pemahaman kepada pembaca bagaimana pentingnya kegiatan evaluasi koleksi bagi para pustakawan. Karya penelitian dari Puspita (2019) menunjukan bagaimana seorang pustakawan mengolah koleksi dengan melakukan katalogisasi. Penelitian Puspita (2019) menunjukan bahwa katalogisasi merupakan kegiatan yang sangat penting sebagai entri bibliografis dan sarana temu kembali informasi bagi pengguna. Penelitian ini memfokuskan pada koleksi DVD Film di 
Perpustakaan PDDI LIPI kawasan Bandung. Penelitian Nelisa dan Ardoni (2018) juga menunjukan bagaimana pustakawan memanfaatkan koleksi demi mendapatkan informasi yang akurat. Untuk memudahkan penelusuran informasi, pustakawan harus mampu menyediakan sarana untuk melakukan temu kembali informasi dengan baik. Selain itu pustakawan juga dapat membuat indeks beranotasi untuk koleksi terbitan berkala, seperti surat kabar, majalah, prosiding dan jurnal ilmiah. Pustakawan juga harus mampu memanfaatkan alat elektronik dan internet untuk memudahkannya dalam membantu pengunjung menemukan informasi dengan efektif dan efisien.

Tinjauan pustaka di atas menunjukan bahwa kajian mengenai pelayanan dan koleksi perpustakaan belum banyak membahas mengenai koleksi bukan buku, seperti surat kabar, majalah, jurnal dan lain-lain. Kebanyakan peneliti fokus untuk membahas mengenai koleksi buku. Dengan demikian penelitian ini mencoba untuk membahas mengenai koleksi bukan buku yang berupa surat kabar. Selain itu, kajian mengenai pelayanan juga lebih banyak membahas mengenai kepuasan pemustaka atau pengunjung. Belum banyak kajian yang membahas mengenai bagaimana upaya pustakawan memainkan perannya dalam melayani pemustaka, namun tetap fokus juga dalam menjaga kelestarian koleksi langka. Untuk itu penelitian ini membahas bagaimana pelayanan perpustakaan dapat memberikan manfaat kepada pengunjung atau pemustaka, namun juga tetap fokus dalam menjaga kelestarian koleksi.

\section{METODE}

Penelitian ini ditulis dengan menggunakan metode kuantitatif melalui pendekatan observasi lansung. Metode kuantitatif adalah metode yang menggunakan data-data kuantitatif yang kemudian diinterpretasikan menjadi suatu argumentasi. Dengan menggunakan metode kuantitatif, penulis melakukan penelusuran terhadap data-data dari surat kabar prakemerdekaan yang ada di Perpustakaan Nasional RI. Data tersebut disusun agar diketahui berapa jumlah surat kabar prakemerdekaan yang ada di sana. Setelah itu penulis menghitung juga jumlah surat kabar yang sudah dialihmedia dalam 
bentuk mikrofilm. Untuk data pengunjung, penulis menggunakan data buku tamu dan permintaan bon sehingga dapat diketahui berapa pengunjung yang meminta surat kabar prakemerdekaan. Setelah data-data tersebut didapatkan, penulis dapat melakukan analisis mengenai pelayanan surat kabar prekemerdekaan di Perpustakaan Nasional RI. Pendekatan dalam penelitian ini adalah observasi langsung. Dalam hal ini, penulis melakukan pengamatan kondisi di lapangan secara langsung. Penulis melakukan pengamatan bagaimana cara kerja para pustakawan hingga kondisi fisik dari surat kabar prakemerdekaan.

\section{HASIL DAN PEMBAHASAN}

Pelayanan merupakan salah satu kegiatan perpustakaan yang sangat penting. Kualitas pelayanan akan menentukan kepuasan para pengunjung dalam memanfaatkan koleksi perpustakaan. Pelayanan perpustakaan yang baik harus didukung oleh kemampuan pustakawan dalam memberikan informasi kepada pengunjung. Selain itu, perkembangan teknologi juga menentukan kualitas pelayanan terhadap masyarakat yang ingin mendapatkan informasi. Teknologi internet semakin memudahkan masyarakat untuk mendapatkan informasi dengan cepat tanpa harus datang ke perpustakaan. Namun, banyaknya informasi itu juga justru semakin mempersulit masyarakat untuk mendapatkan informasi tepat yang dibutuhkan (Putra \& Irawati, 2018). Dengan demikian peran pustakawan sangatlah penting dalam menemukan informasi ditengah perkembangan teknologi abad ke-21.

Pelayanan perpustakaan dapat dilakukan dengan sistem tertutup, terbuka dan campuran (Yehuda, 2017). Pelayanan sistem tertutup merupakan pelayanan koleksi terhadap pengunjung dengan melarang pengunjung mencari dan menyentuh koleksi sendiri secara langsung. Biasanya layanan ini dilakukan di beberapa perpustakaan penting, seperti perpustakaan nasional atau perpustakaan khusus yang menyimpan karya-karya langka. Salah satu tujuan dilakukannya layanan tertutup adalah untuk melindungi koleksi agar tidak mudah rusak atau hilang. Biasanya layanan ini dilakukan pada kelompok layanan koleksi-koleksi langka, seperti naskah kuno, surat 
kabar langka, majalah langka, hingga buku langka. Dalam layanan ini peran pustakawan sangat besar dalam melakukan temu kembali informasi. Sedangkan ada juga layanan terbuka yang memungkinkan pengunjung untuk mencari dan mengakses koleksi secara langsung. Biasanya layanan terbuka diterapkan pada perpustakaan umum yang menyimpan koleksi-koleksi terbaru sehingga jika ada koleksi yang hilang atau rusak, pustakawan dapat mendapatkan kembali gantinya dengan mudah.

Perpustakaan Nasional Republik Indonesia merupakan perpustakaan nasional yang bertempat di ibu kota Jakarta. Perpustakaan ini memiliki dua sistem pelayanan, yaitu pelayanan terbuka dan tertutup. Beberapa layanan terbuka diantaranya adalah layanan Kelompok Monograf Terbuka, Layanan Anak, Layanan Koleksi Nusantara, Layanan Koleksi Mancanegara dan lainlain. Dalam kelompok ini pengunjung dapat diperbolehkan mencari dan mengambil koleksi secara langsung. Perpustakaan Nasional RI juga memiliki beberapa kelompok dengan layanan tertutup, seperti Layanan Majalah Terjilid, Layanan Surat Kabar Langka, Layanan Naskah Kuno, Layanan Buku Langka dan lain-lain. Dalam layanan tertutup, pustakawan biasanya berperan besar dalam mencarikan koleksi dan memberikannya kepada pengunjung.

Penelitian ini membahas mengenai pelayanan surat kabar prakemerdekaan yang ada di Perpustakaan Nasional RI. Hal ini merupakan respon atas kurangnya kajian mengenai koleksi bukan buku, khususnya surat kabar, dalam penelitian bidang ilmu perpustakaan. Surat kabar merupakan media komunikasi cetak yang diterbitkan secara berkala dan berfungsi untuk memberikan informasi berita maupun kejadian di suatu wilayah, baik dalam ruang lingkup lokal, nasional maupun internasional. Surat kabar memuat berbagai macam informasi, baik itu berita, iklan, opini, hingga tajuk rencana. Di Indonesia, surat kabar sudah ada sejak abad ke-17 ketika Jawa masih dikuasai oleh Perusahaan Hindia Belanda Timur (VOC). Sejak itu surat kabar berkembang dengan pesat hingga hari ini. Surat kabar prakemerdekaan merupakan surat kabar yang terbit sebelum masa kemerdekaan Indonesia tahun 1945. Dengan demikian, surat kabar prakemerdekaan dapat disebut dengan surat kabar masa penjajahan. Surat kabar tertua yang dimiliki oleh 
Perpustakaan Nasional RI adalah Bataviaasch Kolonial Kourant yang terbit pada tahun 1810. Untuk itu penelitian ini mendefinisikan bahwa surat kabar prakemerdekaan adalah surat kabar yang terbit di Indonesia atau Hindi Belanda antara tahun 1810 hingga 1945.

Layanan Surat Kabar Langka merupakan kelompok kerja yang berada di bawah kontrol Pusat Jasa Perpustakaan dan Informasi, Perpustakaan Nasional RI. Layanan ini berada di Perpustakaan Nasional RI di Jalan Salemba Raya No.28A, Senen, Jakarta Pusat, DKI Jakarta. Kelompok layanan ini bertugas untuk memberikan pelayanan koleksi surat kabar langka dari zaman Hindia Belanda hingga tahun 2014. Dengan demikian hal ini berbeda dengan layanan surat kabar mutakhir yang berada di Perpustakaan Nasional RI di Jalan Merdeka Selatan. Kelompok Layanan Surat Kabar Langka berada di lantai 7 Gedung B dan C, lantai 8 Gedung C dan 9 Gedung C, Gedung Salemba. Namun, ruang baca untuk pengunjung berada di lantai 7 Gedung C. Para pengunjung tidak dapat mencari koleksi surat kabar langka secara langsung karena kelompok ini menerapkan sistem layanan tertutup. Pengunjung dapat melakukan pemesanan koleksi melalui bon permintaan atau mengisi Google Form yang disediakan oleh pustakawan.

Hingga saat penelitian ini ditulis (Juli 2020), Layanan Surat Kabar Langka memiliki tujuh pustakawan dan tiga pegawai pengadministrasian umum. Dari tujuh pustakawan, satu diantaranya merupakan Pustakawan Ahli Madya. Kemudian ada satu pustakawan tingkat Pustakawan Ahli Muda dan terdapat lima Pustakawan Ahli Pertama. Jika dilihat dari latar belakang pendidikan, maka terdapat enam orang pustakawan yang berlatar belakang ilmu perpustakaan dan satu orang berlatar belakang pendidikan dari ilmu sejarah. Para pustakawan yang bekerja di Layanan Surat Kabar Langka tidak ada yang berasal dari latar belakang sastra asing, khususnya sastra Belanda. Namun, para pustakawan di Layanan Surat Kabar Langka juga tetap mempelajari bahasa Belanda dengan cara otodidak. Hal tersebut sangatlah penting karena surat kabar prakemerdekaan banyak yang diterbitkan dalam bahasa Belanda. Berikut adalah grafik dari pegawai di Layanan Surat Kabar Langka. 


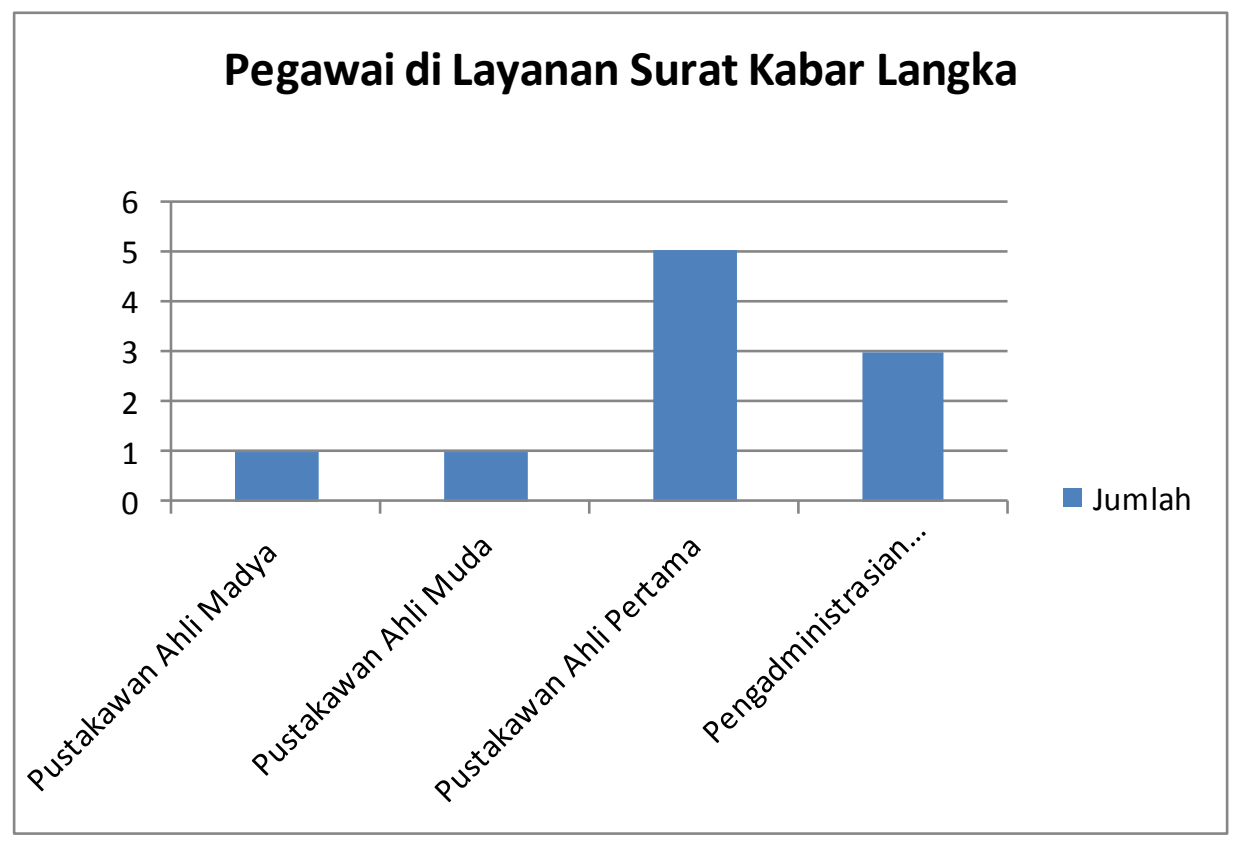

\section{Gambar 1. Grafik Pegawai di Layanan Surat Kabar Langka}

Sumber: Penelitian 2020

Para pengunjung yang datang ke Layanan Surat Kabar Langka biasanya memesan berbagai macam surat kabar dari mulai surat kabar zaman Hindia Belanda hingga zaman kontemporer. Mereka yang datang ke Layanan Surat Kabar Langka terdiri dari berbagai profesi dan latar belakang. Mereka tidak hanya mencari surat kabar berbahasa Melayu, tetapi juga surat kabar berbahasa Belanda, Prancis, Jepang, Cina, Arab dan bahasa daerah, seperti Batak, Sunda dan Jawa. Sebelum Indonesia merdeka tahun 1945, surat kabar terdiri dari berbagai macam bahasa. Bahasa Belanda tentu saja menjadi bahasa utama dalam bisnis surat kabar karena surat kabar menjadi media komunikasi para pebisnis, khususnya pebisnis Belanda. Selain itu, surat kabar juga menjadi media pemerintah kolonial Belanda untuk mengumumkan kejadian suatu peristiwa atau aturan hukum baru. Dengan demikian, bahasa Belanda menjadi bahasa yang sangat penting dalam bisnis surat kabar. Bahasa Belanda menjadi prasyarat untuk masuk menjadi elite modern di Hindia 
Belanda. Bahkan surat kabar Jong Java (terbit antara tahun 1920 hingga 1929) yang bertujuan membawa kebangkitan para murid-murid Jawa sendiri terbit dalam bahasa Belanda. Setelah itu ada juga surat kabar yang terbit dalam bahasa Arab dan Cina. Surat kabar Hadramaut merupakan surat kabar berbahasa Arab yang terbit di Indonesia pada awal abad ke-20. Beberapa surat kabar berbahasa Cina juga dimiliki oleh Layanan Surat Kabar Langka, seperti Kung Yen, Kong Hoa Po, Min Pao. Setelah Jepang masuk ke Indonesia pada 1942, muncul beberapa surat kabar berbahasa Jepang. Layanan ini juga memiliki surat kabar yang terbit dalam bahasa daerah, seperti Sipatahoenan (bahasa Sunda), Sarotomo (bahasa Jawa) dan lain-lain. Untuk itu pustakawan yang bekerja di Layanan Surat Kabar Langka harus memiliki kemampuan dalam membaca koleksi yang terdiri dari berbagai macam bahasa.

Penelitian ini difokuskan pada pelayanan surat kabar zaman prakemerdekaan. Para pengunjungyang memesan surat kabar prakemerdekaan biasanya adalah para peneliti yang sedang melakukan proyek penelitian, baik itu untuk skripsi, tesis, disertasi atau kebutuhan penelitian untuk membuat karya tulis ilmiah. Namun, ada juga yang datang karena tertarik dengan berbagai tema-tema sejarah. Berdasarkann data pengunjung yang berhasil dihimpun, dari bulan Januari hingga Juni 2020 terdapat 1.632 bon permintaan secara elektronik melalui aplikasi Google Form. Para pengunjung meminta berbagai macam surat kabar baik itu Kompas, Suara Pembaharuan, Adil, Soeara Oemoem dan lain-lain.

Permintaan terhadap surat kabar prakemerdekaan tidak lebih banyak daripada surat kabar pasca kemerdekaan. Antara bulan Januari hingga Juni 2020, dari 1.632 bon permintaan, hanya terdapat 183 bon permintaan surat kabar prakemerdekaan. Tentu saja jumlah tersebut sangat sedikit. Dengan demikian, dalam enam bulan hanya terdapat 11,2 persen saja permintaan surat kabar prakemerdekaan. Berdasarkan hal tersebut, dapat disimpulkan bahwa permintaan surat kabar pasca kemerdekaan mendominasi permintaan surat kabar di Layanan Surat Kabar Langka dengan permintaan sebesar 88,8 persen dari jumlah permintaan. Berikut adalah diagram permintaan surat kabar langka dari Januari hingga Juni 2020. 


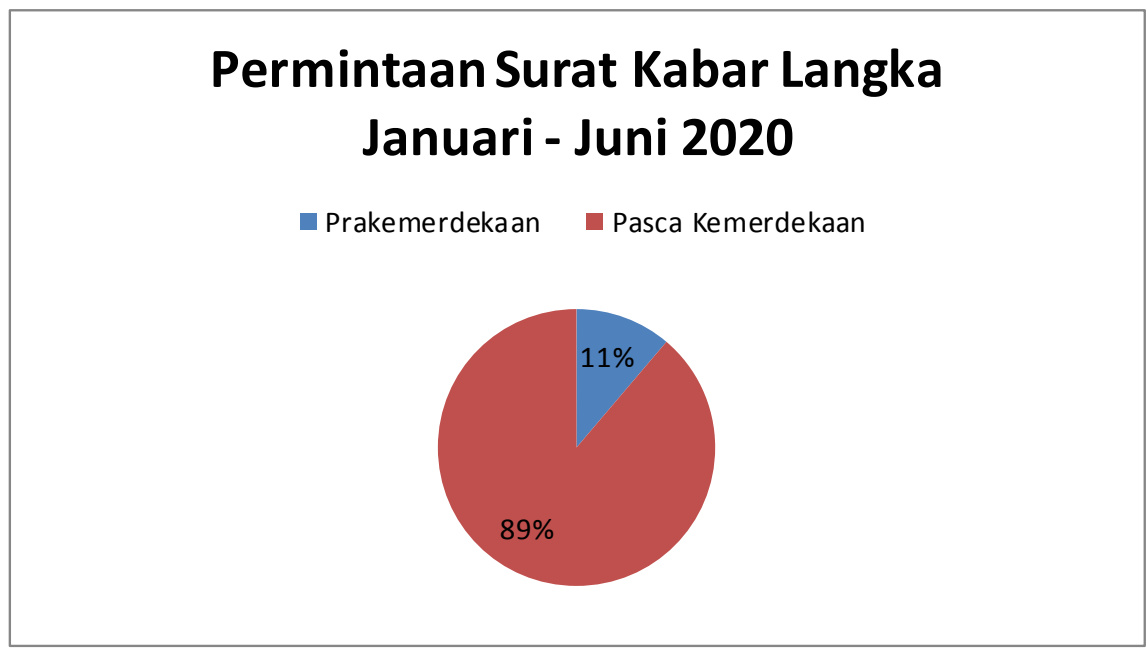

\section{Gambar 2. Diagram Permintaan Surat Kabar Prakemerdekaan}

Sumber: penelitian 2020

Permintaan untuk membaca surat kabar prakemerdekaan sangatlah sedikit. Hal tersebut dapat diketahui karena surat kabar prakemerdekaan merupakan surat kabar yang sudah sangat tua dan tidak semua orang membutuhkan informasi mengenai masa lampau. Dalam dunia akademik, para peneliti yang membutuhkan surat kabar sebelum tahun 1945 biasanya adalah para sejarawan atau ahli ilmu-ilmu sosial kebudayaan yang melakukan penelitian dengan pendekatan ilmu sejarah. Selain itu, surat kabar prakemerdekaan tidak menggunakan bahasa Indonesia modern sehingga tidak mudah untuk dibaca oleh masyarakat umum. Bahkan, surat kabar prakemerdekaan dari zaman kolonial Belanda (1810-1942) menggunakan bahasa Belanda yang sedikit diketahui dan dipahami, baik oleh peneliti Indonesia maupun kalangan masyarakat umum. Pada awal abad ke-20 mulai muncul banyak surat kabar yang menggunakan bahasa Melayu. Namun bahasa tersebut belum memakai Ejaan Yang Disempurnakan (EYD).

Salah satu permasalahan yang terjadi dalam pelayanan surat kabar prakemerdekaan adalah buruknya kondisi fisik surat kabar karena umur surat kabar tersebut sudah sangat tua. Layanan Surat Kabar Langka memiliki 
dua ruang koleksi yang berada di lantai 8 Gedung C dan lantai 9 Gedung C. Surat kabar zaman prakemerdekaan disimpan di kedua gedung tersebut dan disatukan dengan koleksi surat kabar pasca kemerdekaan. Di dalam ruang koleksi tersedia rak dan mesin pendingin (AC) untuk menjaga agar surat kabar tidak mudah rusak. Meskipun demikian, banyak surat kabar prakemerdekaan yang sudah tidak memiliki kondisi fisik yang baik. Beberapa kriteria surat kabar prakemerdekaan yang kondisi fisiknya sudah buruk adalah kertas rapuh, robek, tidak dilindungi oleh bundel/portapel, berjamur, dan terdapat banyak kutu. Namun kertas yang robek menjadi salah satu faktor paling utama dalam kerusakan fisik surat kabar prakemerdekaan. Para pengunjung yang memesan surat kabar prakemerdekaan yang sudah rusak kondisi fisiknya akan disarankan untuk mengakses surat kabar yang sudah dialihmedia menjadi mikrofilm. Sebenarnya Perpustakaan Nasional RI juga sudah melakukan digitalisasi terhadap beberapa judul surat kabar. Hal tersebut dapat ditemukan dalam Khastara (Khazanah Nusantara) yang tersedia di laman resmi Perpustakaan Nasional RI. Namun, hanya ada delapan judul surat kabar yang dialihmedia dalam bentuk digital. Jumlah tersebut sangat sedikit jika dibandingkan dengan jumlah seluruh judul surat kabar yang dimiliki oleh Perpustakaan Nasional RI. Dengan demikian, penelitian ini hanya akan fokus pada koleksi fisik surat kabar langka.

Koleksi surat kabar berbentuk mikrofilm berada di Layanan Audio Visual, Perpustakaan Nasional RI, Jalan Merdeka Selatan. Tidak semua surat kabar prakemerdekaan sudah dialihmediakan ke dalam bentuk mikrofilm. Untuk itu, penulis melakukan pendataan mengenai surat kabar prakemerdekaan yang ada di Perpustakaan Nasional RI. Berdasarkan penelitian yang dilakukan oleh penulis, maka Layanan Surat Kabar Langka memiliki 526 judul surat kabar prakemerdekaan. Semuanya terdiri dari berbagai macam bahasa, baik itu bahasa Belanda, Melayu, Sunda, Jawa, Batak, Prancis, Jepang, Inggris dan lain-lain. Dari 526 judul surat kabar prakemerdekaan, 292 judul sudah dialihmediakan ke dalam bentuk mikrofilm. Dengan demikian jika dilihat presentasenya, maka 55, $5 \%$ surat kabar prakemerdekaan sudah dialihmediakan ke dalam bentuk mikrofilm. 
Dari 292 judul surat kabar prakemerdekaan yang berbentuk mikrofilm, tidak semua edisi sudah berbentuk mikrofilm. Ada yang sebagian edisinya saja yang sudah berbentuk mikrofilm, dan sebagian lagi belum berbentuk mikrofilm. Namun, ada juga surat kabar yang seluruhnya sudah berbentuk mikrofilm. Surat kabar Tjahaja Timoer, misalnya, tidak semuanya sudah berbentuk mikrofilm. Surat kabar yang terbit di Malang antara tahun 1914-1942 ini yang sudah berbentuk mikrofilm adalah antara tahun 1914 hingga 1937 saja. Sedangkan sisanya masih berbentuk lembaran surat kabar. Surat kabar Padangsch Nieuws-en Advertentieblad yang terbit antara tahun 1859-1862 tidak semuanya sudah berbentuk mikrofilm. Hanya yang terbit antara 1859 hingga 1861 saja yang sudah berbentuk mikrofilm. Sementara banyak juga surat kabar yang sudah berbentuk mikrofilm secara keseluruhan. Beberapa surat kabar yang sudah berbentuk mikrofilm secara keseluruhan adalah, seperti Padjadjaran, Pandji rajat, Panggoegah, Pantjaran Berita, Pemberita Makassar, Pengadilan dan lain-lain.

Berdasarkan penelitian ini, maka didapatkan bahwa hanya 138 surat kabar prakemerdekaan yang semua edisinya sudah berbentuk mikrofilm. Surat kabar yang semua edisinya sudah berbentuk mikrofilm terdiri dari surat kabar berbahasa Belanda, Jepang, Melayu dan beberapa bahasa daerah. Diantara surat kabar berbahasa Belanda yang semua edisinya sudah berbentuk mikrofilm adalah De Zondag Courant, De Volksteem, De Vakbeweging, De Telefoon, Sport, Soerabaiasch, Soearabaiasch Advertentieblad, De Scheepvaart, De Preanger Post, Prange's nieuws en advertentieblad, Perdamean's Oost Indisch nieuws-handels \& Advertentieblad dan lain-lain. Sedangkan surat kabar Melayu yang seluruh edisinya sudah berbentuk mikrofilm adalah seperti Pengadilan, Pemberita Makassar, Pantjaran Berita, Pandji ra'jat, Panggoegah, Padjadjaran, Oetoesan Melajoe dan lain-lain.

Para peneliti yang ingin melakukan pencarian informasi surat kabar prakemerdekaan bergantung pada kondisi fisik surat kabar. Pustakawan yang bekerja di Layanan Surat Kabar Langka harus memiliki ketelitian dan kecermatan dalam melihat kondisi fisik surat kabar prakemerdekaan karena surat kabar ini merupakan koleksi langka dan tua sehingga sangat berharga. 
Untuk itu pustakawan harus berhati-hati dalam memutuskan apakah surat kabar yang diminta boleh diberikan atau tidak. Pustakawan yang bekerja di Layanan Surat Kabar Langka juga akan melihat kondisi fisik surat kabar prakemerdekaan terlebih dahulu sebelum memberikan koleksi tersebut kepada pengunjung untuk dibaca. Setelah kondisi surat kabar tersebut diperiksa, maka pustakawan yang bekerja di Lantai 8 dan 9 akan memberikan keputusan apakah surat kabar yang diminta tersebut boleh diberikan kepada pengunjung atau tidak. Setelah diberikan keputusan, maka pustakawan yang bertugas di lantai 7 akan menginformasikan keputusan mengenai koleksi surat kabar prakemerdekaan yang diminta oleh pengunjung tersebut. Berikut adalah tabel teknis pemberian surat kabar prakemerdekaan.

\section{Tabel 1. Teknis pemberian surat kabar prakemerdekaan}

\begin{tabular}{llll}
\hline & \multicolumn{1}{c}{ Kondisi Fisik } & \multicolumn{1}{c}{ Ada Mikrofilm } & Tidak Ada Mikrofilm \\
\hline Baik & $\begin{array}{l}\text { Lembaran masih kuat, } \\
\text { bundel baik, dan tidak } \\
\text { berjamur. }\end{array}$ & Diberikan & Diberikan \\
\hline $\begin{array}{l}\text { Rusak } \\
\text { Ringan }\end{array}$ & $\begin{array}{l}\text { Lembaran sebagian } \\
\text { kecil rusak, bundel } \\
\text { hampir rusak, } \\
\text { berjamur. }\end{array}$ & $\begin{array}{l}\text { Disarankan mengakses } \\
\text { Layanan Audio Visual }\end{array}$ & $\begin{array}{l}\text { Diberikan dengan } \\
\text { pengawasan } \\
\text { pustakawan }\end{array}$ \\
\hline $\begin{array}{l}\text { Rusak } \\
\text { Berat }\end{array}$ & $\begin{array}{l}\text { Lembaran sebagian } \\
\text { besar rusak, bundel } \\
\text { rusak dan berjamur. }\end{array}$ & Tidak diberikan & $\begin{array}{l}\text { Diberikan dengan } \\
\text { pengawasan } \\
\text { pustakawan }\end{array}$ \\
\hline
\end{tabular}

Sumber: Penelitian 2020

Berdasarkan tabel 1, maka dapat dipahami bahwa pustakawan memiliki otoritas untuk menentukan apakah suatu surat kabar prakemerdekaan yang diminta oleh pengunjung boleh dikeluarkan atau tidak dari ruang koleksi. Hal tersebut bergantung pada kondisi fisik surat kabar dan ketersediaan versi mikrofilmnya. Pustakawan juga memiliki kewajiban untuk melakukan pengawasan terhadap pengunjung yang mengakses surat kabar 
prakemerdekaan, khususnya jika surat kabar tersebut dalam kondisi rusak ringan dan rusak berat. Dalam hal ini, pustakawan juga akan menyarankan pengunjung untuk pergi ke Layanan Audio Visual yang menyimpan koleksi mikrofilm. Layanan ini tidak berada satu gedung dengan Layanan Surat Kabar Langka karena Layanan Audio Visual berada di Perpustakaan Nasional Republik Indonesia di Jalan Merdeka Selatan.

Para pengunjung yang tidak dapat membaca surat kabar prakemerdekaan secara fisik, tentu saja, harus berkunjung ke Layanan Audio Visual. Sejak pindahnya sebagian besar koleksi dari Perpustakaan Nasional RI di Jalan Salemba Raya ke gedung baru di Jalan Merdeka Selatan pada 2017, koleksi Layanan Surat Kabar Langka terpisah dengan Layanan Audio Visual yang menyimpan koleksi surat kabar dalam bentuk mikrofilm. Dengan demikian, para pengunjung yang tidak dapat membaca surat kabar prakemerdekaan secara langsung harus pergi menuju ke gedung Perpustaakaan Nasional RI di Jalan Merdeka Selatan. Dengan demikian, para pustakawan harus melakukan koordinasi dengan ekstra untuk melakukan penyesuaian antara koleksi surat kabar langka dengan koleksi mikrofilm. Jika surat kabar prakemerdekaan yang diminta belum dialihmediakan ke dalam mikrofilm dan ingin membaca fisik surat kabar tersebut, maka pemustaka harus menunjukan surat penelitian kepada pustakawan. Hal tersebut berguna untuk melihat seberapa besar kepentingan pemustaka untuk mengakses surat kabar tersebut.

\section{KESIMPULAN}

Surat kabar prakemerdekaan merupakan koleksi yang sangat penting di Perpustakaan Nasional Republik Indonesia. Meskipun demikian, minat pemustaka untuk membaca surat kabar prakemerdekaan masih sangat kecil, jika dibandingkan minat membaca surat kabar pasca kemerdekaan. Berdasarkan periode penelitian ini, maka permintaan surat kabar prakemerdekaan dari bulan Januari hingga Juni 2020 hanya sebesar 11,2 $\%$ saja dari seluruh permintaan. Hal tersebut menunjukan bahwa minat pemustaka untuk membaca surat kabar prakemerdekaan sangat kecil. 
Di samping itu, kondisi fisik surat kabar prakemerdekaan sudah banyak yang rusak. Namun, hampir 55,5 \% surat kabar prakemerdekaan sudah dialihmediakan ke dalam bentuk mikrofilm. Pustakawan memiliki peran yang penting dalam melayani dan menjaga surat kabar prakemerdekaan. Jika surat kabar prakemerdekaan yang diminta sudah dalam kondisi rusak, maka pustakawan mengarahkan para pemustaka untuk membaca surat kabar prakemerdekaan dalam bentuk mikrofilm di Layanan Audio Visual.

\section{DAFTAR PUSTAKA}

Adam, Ahmat. Sejarah Awal Pers dan Kebangkitan Kesadaran Keindonesiaan. ( Jakarta: Hasta Mitra, 2003).

Hanany, Neilah Hanum., \& Sudirman, Eded., “ Kepuasan pemustaka Perpustakaan UIN Sunan Gunung Djati Bandung dan pengaruh word of mouth pemustaka," Jurnal Kajian Informasi \& Perpustakaan.7, No. 1 (2019): 95-112. https://doi.org/10.24198/jkip.v7i1.19130

Muhammad, Ilham Nur., Komariah, Neneng., \& Kurniasih, Nuning, "Tindakan vandalisme di Perpustakaan Fakultas Ilmu Komunikasi Universitas Padjadjaran," Jurnal Kajian Informasi \& Perpustakaan.7. No.1 (2019): 81-94. https://doi.org/10.24198/jkip.v7i1.17757

Nelisa, Malta, \& Ardoni, "Penelusuran informasi pada pemustaka Universitas Negeri Padang," Pustabiblia.2. No.1 (2018): 55-70. https://doi. org/10.18326/pustabiblia.v2i1.55-70

Oktaviani, Hervinda Raana., Saifudin, \& Puspita, Rosana Eri, “Kualitas layanan sebagai strategi peningkatan kepuasan pengunjung perpustakaan," Pustabiblia.3. No.2 (2019): 159-174. https://doi. org/10.18326/pustabiblia.v3i2.159-174

Puspita, Rosana Eri, "Kegiatan katalogisasi dalam pengolahan koleksi DVD film di Kepustakaan PDDI LIPI kawasan Bandung." Pustabiblia.3. No.2 (2019): 127-140. https://doi.org/10.18326/pustabiblia.v3i2.127140 
Putra, Irwin Pratama., \& Irawati, Indira., "Layanan referensi sebagai representasi perpustakaan perguruan tinggi." Jurnal Kajian Informasi dan Perpustakaan.6. No.1 (2018): 77-94. https://doi.org/10.24198/jkip. v6i1.13464

Supratman, Frial Ramadhan, "Koleksi surat kabar langka Perpustakaan Nasional Republik Indonesia sebagai sumber penelitian sejarah global." Jurnal Kajian Informasi dan Perpustakaan.8. No. 1 (2020): 85-100. https://doi.org/10.24198/jkip.v8i1.25212

Usman \& Narani, Siti., “Pengelolaan Perpustakaan Madrasah di Kota Palangka Raya (Kajian terhadap upaya madrasah menjadikan perpustakaan sebagai sumber belajar dan bagian dari sistem pengajaran)," Pustabiblia. 4 No.1 (2020): 79-110. http://dx.doi.org/10.18326/ pustabiblia.v4i1.79-110

Yehuda, Yesaya., "Sistem pelayanan terbuka pada interior Perpustakaan Umum di Semarang," Jurnal Intra..5. No.2 (2017): 964-969. http:// publication.petra.ac.id/index.php/desain-interior/article/view/6050 